\title{
INTERRELATION BETWEEN TENSILE PROPERTIES OF YARNS AND WOVEN FABRICS WITH THESE YARNS
}

\author{
Eglè Kumpikaitè, Indrè Tautkutè-Stankuvienè, Dovilè Redeckienè
}

Department of Production Engineering, Kaunas University of Technology, Studentu Street 56, LT-51424 Kaunas, Lithuania, tel.: +370 37 353862; e-mail: egle.kumpikaite@ktu.It

\begin{abstract}
:
The main parameters of tensile tests for fabrics and yarns are the breaking force and the elongation at break. The aim of this investigation was to find the relation between the tensile properties of yarns and woven fabrics for different natural raw materials. Manmade bamboo, natural single flax, blended plied flax and natural silk yarns, plied combed cotton yarns, blended plied cotton, and polyester yarns were used for the research. The warp of almost all fabrics, except of one fabric, was from flax. This fabric was woven using blended flax and silk yarns in the warp. Weft yarns were more various - yarns of one kind were used in the weft for certain fabrics; yarns of two kinds were used in 1:1 repeats in other fabrics. It was established that the breaking force for both woven fabrics and yarns increases when the elongation at break increases. The relationships between the tensile parameters of yarns and woven fabrics were established. The results showed weak dependence between the tensile parameters of yarns and fabrics because the coefficients of determination of the dependences are small.
\end{abstract}

\section{Keywords:}

woven fabric; yarn; raw material; breaking force; elongation at break

\section{Introduction}

Two of the main mechanical properties of a woven fabric are its strength and elasticity. The breaking force and elongation at break are the most common characteristics of these mentioned fabric properties.

Kumpikaitè and Sviderskytè [1] obtained the dependencies of breaking force and elongation at break for different weave factors. The point diagrams show that there is no correlation between fabrics' breaking force and elongation at break, but elongation at break depends on the fabric's weave factors, i.e., when the fabric stiffness increases, elongation at break increases. Dependencies of breaking force and elongation at break on the fabric's weft setting were established as well. The results show that when the weft setting increases, the breaking force slowly decreases and the elongation at break increases. Based on the dependencies of breaking force and elongation at break on the integrated fabric structure factors, it can be seen that there is no correlation between the breaking force and the integrated fabric structure factors, and elongation at break increases when the fabric structure becomes stiffer [1, 2].

Kumpikaite $[3,4]$ analyzed the influence of fabric structure, which was expressed by the integrated fabric structure factor, on the breaking force and the elongation at break. Weaves were divided into two groups, i.e., weaves in which floats are distributed evenly in the whole fabric surface, and horizontally striped weaves. The author established that fabric breakage in different weave groups differs. It was estimated that the dependence between the breaking force and the fabric structure is not clearly visible on the fabrics investigated. The change intensity of dependencies of elongation at break on this factor for horizontally striped fabrics was lower than for weaves with equally distributed floats. When this factor increases, elongation at break has the tendency to decrease at first; but when the factor reaches $0.45-0.50$ or higher values, elongation at break rises. Breaking force in the warp direction for weaves with evenly distributed floats is lower than for horizontally striped weaves. Dependence of the breaking force on this factor in the warp direction at first has a tendency to decrease, but when the factor reaches a certain value, the fabric's breaking force starts to increase. Dependence of elongation at break on this factor for horizontally striped weaves is weaker than that for weaves with evenly distributed floats $[3,4]$.

Rathod and Kolhatkar [5] investigated the physical properties of fabrics from bamboo fibers and blended bamboo/cotton (50:50) yarns. These fabrics are commonly used for clothes. Results of the analysis of the properties of different fabrics show that fabrics from $100 \%$ bamboo have higher abrasion resistance than fabrics from bamboo/cotton (50:50). In addition, elongation at break is higher for fabrics from $100 \%$ bamboo than for fabrics from bamboo/cotton (50:50) [5].

Parameters of the warp and weft threads influence the fabric's breaking force. Their various properties (raw material, linear density, and structure) influence the character of the stressstrain curves as well as the fabric breaking force in the warp and weft directions [6, 7].

The fabric's breaking force and elongation at break depend on the used yarns and their breaking forces, as well as the 
elongation at break. Scientists Gabrijelčič et al. [8] established that when single and plied twisted yarns are used, the fabric breaking force from plied yarns in the weft direction is higher than that from single yarns.

Gunaydin et al. [9] investigated the influence of different compositions of different cotton fiber blends (American cotton, Aegean cotton, Urfa cotton, and Greek cotton) on the tensile properties of yarns from these blends. It was established that the composition of the cotton blend influences the properties of yarn from these blends.

Azeem et al. [10] analyzed the effect of spinning technologies and weave on the fabric's mechanical and surface properties. Ring spun (combed, carded) and open-end techniques were used to manufacture yarns of polyester cotton (50:50) in the weft and $100 \%$ cotton yarn in the warp. Plain, twill, and satin weaves were used for the fabrics. Higher interlacing of yarn produces more crimp in the load bearing, which causes lower breaking force and fewer broad floats. A significant effect of the spinning technique and weave on these properties was established.

Zajączkowski [11] presented the mathematical modeling of textiles subjected to one-directional tensile forces. The model includes straightening of fibers at the beginning, accompanied by the compression of neighboring fibers, and the elongation of the fiber materials when straightening stops increasing. As the result of fiber stretching, the transverse compressive forces hold all the fibers together and are responsible for maintaining the friction forces. Two models are proposed: the rhombus, representing perpendicular fibers, and the helix, representing parallel fibers. The final equations describing both models are found to be the same.

Zubair et al. [12] introduced a new approach to predict the specific stress-strain curves of cotton carded and combed yarns. The force on a single fiber is worked out, and these fiber forces are combined together to obtain the forces acting on the yarn. The theoretical model introduces the utilization of fiber stress on the basis of the fiber-specific stress-strain curve, twist angle, fiber directional distribution parameter $C$, and the contraction ratio. A comparison of the experimental results suggests that the specific stress-strain curves predicted correspond with the experimental yarn-specific stress-strain curves for all types of yarns.

Matusiak and Wilk [13] stated that the weave and the method of layer connection in double-layered fabrics significantly influence the properties of fabrics. The investigated fabric variants were manufactured from the same yarn on the same loom at the same preliminarily established warp and weft densities. The differences in fabric structure resulted from the applied weaves of both layers and the method of layer connection. Both factors influenced the relaxation process after the fabrics were taken off the loom and the behavior of the fabrics in the finishing processes. In addition, they influenced the final structure and properties of fabrics.

Maqsood et al. [14] compared different mechanical and comfort-related properties of fabrics produced from different weave structures and fabric densities. The tensile strength of fabrics produced from plain weave was greater than the tensile strength of fabrics produced from twill weaves due to the greater number of interlacements per unit.

In a previous paper [15], the practical application of the one-axial testing of a painting canvas for determining its mechanical properties was presented. Experimental testing and determination of the mechanical properties of the painting canvas under a tensile force at different angles in relationship to the weft direction were discussed. The values of the tensile force in relation to the relative extension of the coated textiles, as well as the values of breaking force, elongation at break, contraction at break, and work to rupture, were obtained. All these parameters increase with the increase in the number of coated layers, and, at the same time, the coefficient of anisotropy decreases.

Another paper [16] presents an investigation of seersucker fabrics. The type of weft yarn significantly influences the structural and mechanical properties of the fabrics investigated. The type of weft yarn influences the properties of seersucker fabrics in both warp and weft directions. Especially, an application of the elastomeric yarn in the weft caused the tightening of the structure of the fabric in the weft direction, resulting in radical changes of all structural and mechanical properties of the fabric.

Thus, after the literature analysis, it was found that the breaking force and the elongation at break were analyzed for woven fabrics of different raw materials, but the dependencies of these fabrics' properties on certain yarn properties were not analyzed. Therefore, the aim of this research was to find the relationship between the tensile test parameters of yarns and woven fabrics for different natural raw materials.

\section{Materials and methods}

The investigation objects were yarns as well as woven fabrics of different natural raw materials woven in the textile company "Klasikinè Tekstilè" using the investigated yarns.

The main characteristics of the yarns investigated (raw material and linear densities) are presented in Table 1. As can be seen from the table, manmade bamboo, natural single flax, blended plied flax and natural silk yarns, plied combed cotton yarns, and blended plied cotton and polyester yarns were used for the research. During manufacturing, it was noticed that, sometimes, the yarn color used for fabrics also has an influence on the properties of woven fabrics, e.g., comparing fabrics woven from natural-color and dyed yarns. Therefore, black-dyed and natural-color flax yarns were used for the weft of some flax fabrics. Moreover, blended natural yarn from components of a different nature - flax (floral cellulose fiber) and natural silk (animal protein fiber) - were used. It can be seen from Table 1 that the linear density of all used yarns was similar.

Fabrics were woven according to the drawing-in scheme shown in Figure 1. As we can see, the warp was drawn-in in the fancy draft into eight harnesses. 
Table 1. Raw material, structure, and linear density of investigated yarns

\begin{tabular}{|c|c|c|c|}
\hline Yarn & Raw material & Structure & Linear density, tex \\
\hline $\mathbf{J}$ & $100 \%$ bamboo & Single yarn & 30 tex \\
\hline K & $100 \%$ flax & Single yarn & 28 tex \\
\hline $\mathbf{L}$ & $100 \%$ flax, black & Single yarn & 28 tex \\
\hline $\mathbf{M}$ & $86 \%$ cotton $/ 14 \%$ polyester & Plied blended yarn & $(12+2)$ tex ${ }^{\prime} 2$ \\
\hline $\mathbf{N}$ & $70 \%$ flax/30\% silk & Single blended yarn & 28 tex \\
\hline $\mathbf{O}$ & $100 \%$ combed cotton & Plied yarn & 14 tex 2 \\
\hline
\end{tabular}

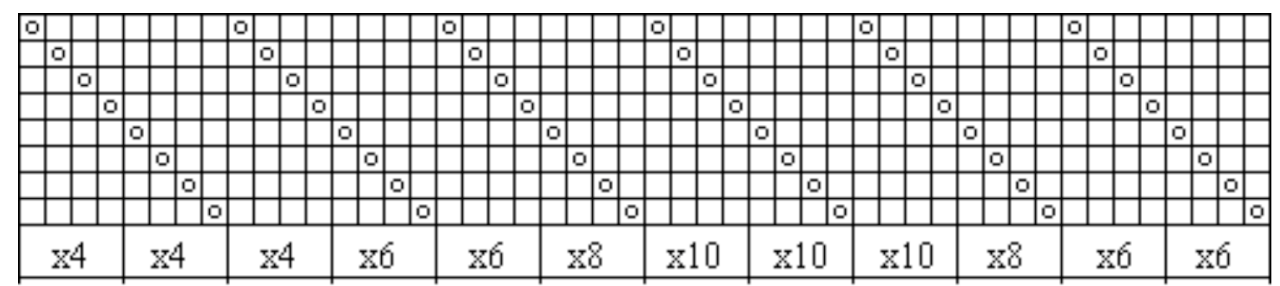

Figure 1. Draft of the fabric

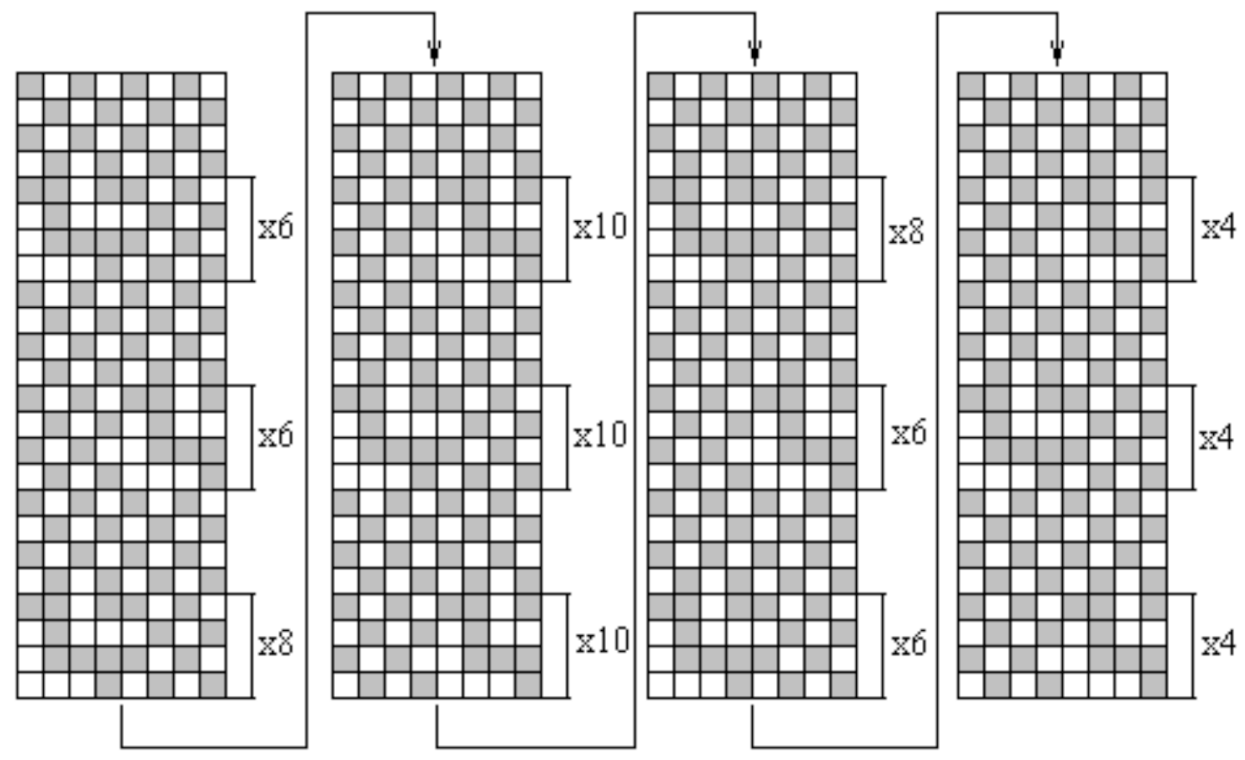

Figure 2. Cards of the fabrics

Cards of woven fabric are presented in Figure 2. Plain weave parts in the fabrics change with plain weave parts.

Double-layer fabrics with changing layers were woven using the yarns from Table 1. Nine double-layer fabrics (loom state and finished) were chosen for the research, because it is important to investigate the influence of finishing on the properties of these fabrics. Different yarn combinations, which are shown in Table 2, were used for the fabrics.

The warps of almost all fabrics, except of fabric A, were from flax. Fabric $A$ was woven using blended flax and silk yarns in the warp. The weft yarns were more various - yarns of one kind (fabrics A, B, and I) were used in the weft for certain fabrics; yarns of two kinds were used in 1:1 repeats in other fabrics (fabrics C, D, E, F, G, and H). The warp of fabrics C, D, E, F, G, and $\mathrm{H}$ was from $100 \%$ flax 28 tex, and the weft was composed of different fibers (flax and silk, flax and combed cotton, flax, cotton, and polyester). The warp of Fabric A was $70 \%$ flax and
$30 \%$ silk 28 tex, and the weft was of the same raw material. The warp and weft were from $100 \%$ flax 28 tex in Fabric B. The warp of Fabric I was made from $100 \%$ flax 28 tex, whereas the weft was from $100 \%$ bamboo 30 tex.

Loom state and finished fabrics were investigated. The same finishing was performed for all fabrics. Fabrics were washed, dyed, rinsed, softened, and dried. All these operations were done in Brongo 100 (Italy). Fabrics were washed for 10-15 min at a temperature of $65^{\circ} \mathrm{C}$, dyed for $75-120 \mathrm{~min}$ at a temperature of $60^{\circ} \mathrm{C}$. Active dyestuff Novotron (Hausmann, Switzerland) was used. Fabrics were rinsed in cold water twice and in hot water twice after dyeing. One rinsing took $5 \mathrm{~min}$. Softening was performed in an acidic environment; the softener Eversol (Japan) was used.

The samples were put on a plain horizontal surface, whereby the weather can go through the fabric, and they were conditioned for at least $24 \mathrm{~h}$ in standard weather conditions 
Table 2. Yarns and setting parameters of investigated fabrics

\begin{tabular}{|c|c|c|c|c|c|c|}
\hline Fabric & $\begin{array}{l}\text { Warp } \\
\text { yarns }\end{array}$ & $\begin{array}{l}\text { Weft } \\
\text { yarns }\end{array}$ & $\begin{array}{l}\text { Warp setting of loom } \\
\text { state fabric, } \mathrm{dm}^{-1}\end{array}$ & $\begin{array}{c}\text { Warp setting of } \\
\text { finished fabric, } \mathrm{dm}^{-1}\end{array}$ & $\begin{array}{l}\text { Weft setting of loom } \\
\text { state fabric, } \mathrm{dm}^{-1}\end{array}$ & $\begin{array}{l}\text { Weft setting of } \\
\text { finished fabric, } \mathrm{dm}^{-1}\end{array}$ \\
\hline A & $\mathrm{N}$ & $\mathrm{N}$ & 218 & 220 & 200 & 223 \\
\hline B & $\mathrm{K}$ & $\mathrm{K}$ & 218 & 220 & 200 & 203 \\
\hline C & $\mathrm{K}$ & $\mathrm{K}$ and $\mathrm{L}$ & 218 & 220 & 200 & 203 \\
\hline D & $\mathrm{K}$ & $\mathrm{K}$ and $\mathrm{M}$ & 218 & 220 & 200 & 223 \\
\hline$E$ & $\mathrm{~K}$ & $\mathrm{~K}$ and $\mathrm{M}$ & 218 & 220 & 200 & 223 \\
\hline $\mathbf{F}$ & $\mathrm{K}$ & $\mathrm{K}$ and $\mathrm{O}$ & 218 & 220 & 200 & 223 \\
\hline G & $\mathrm{K}$ & $\mathrm{L}$ and $\mathrm{O}$ & 218 & 220 & 200 & 223 \\
\hline $\mathbf{H}$ & $\mathrm{K}$ & $\mathrm{K}$ and $\mathrm{N}$ & 218 & 220 & 200 & 206 \\
\hline I & $\mathrm{K}$ & $\mathrm{J}$ & 218 & 220 & 200 & 203 \\
\hline
\end{tabular}

(standard LST EN ISO 139: 2005/A1: 2011 [17]) before testing, i.e., temperature was $(20 \pm 2)^{\circ} \mathrm{C}$ and relative humidity was $(65$ $\pm 4) \%$.

The yarn breaking force and elongation at break were established using the universal tensile machine Zwick/Z005, according to the standard LST EN ISO 2062 [18]. The results from 50 samples were obtained, from which the arithmetic average, the standard deviation, and the coefficient of variation were calculated.

The breaking force and elongation at break for loom state and finished fabrics were established using the universal tensile machine Zwick/Z005 (Switzerland), according to standard ISO 13934-1:1999 [19]. Five strips from each investigated fabric were cut. The width of the strips was $60 \mathrm{~mm} ; 5 \mathrm{~mm}$ fringes were left in each selvage. The sample was fixed over its whole width into the clamps of the tensile machine, where one clamp was stationary and the other clamp moved at a constant speed until the sample broke during the test. The work length of the samples was $200 \mathrm{~mm} \pm 1 \mathrm{~mm}$. Breaking force and elongation at break were established during this test. Arithmetic average, standard deviation, and coefficient of variation were calculated. Tensile tests were performed only in the weft direction, because yarns of different raw materials were mainly used in this direction.

Statistical and regression analyses were done using Microsoft Excel Analysis ToolPak.

\section{Results and discussion}

Seeking to check what influence a yarn's tensile characteristics have on certain properties of fabrics from different raw materials, first, tensile tests were performed on the yarns used for weaving. The yarn breaking force varied from $2.318 \mathrm{~N}$ to $5.673 \mathrm{~N}$, and the coefficient of variation of the breaking force varied from $6.49 \%$ to $26.53 \%$. The values of elongation at break ranged from $1.90 \%$ to $15.19 \%$, and the coefficient of variation varied in the range of $5.93 \%-21.01 \%$.

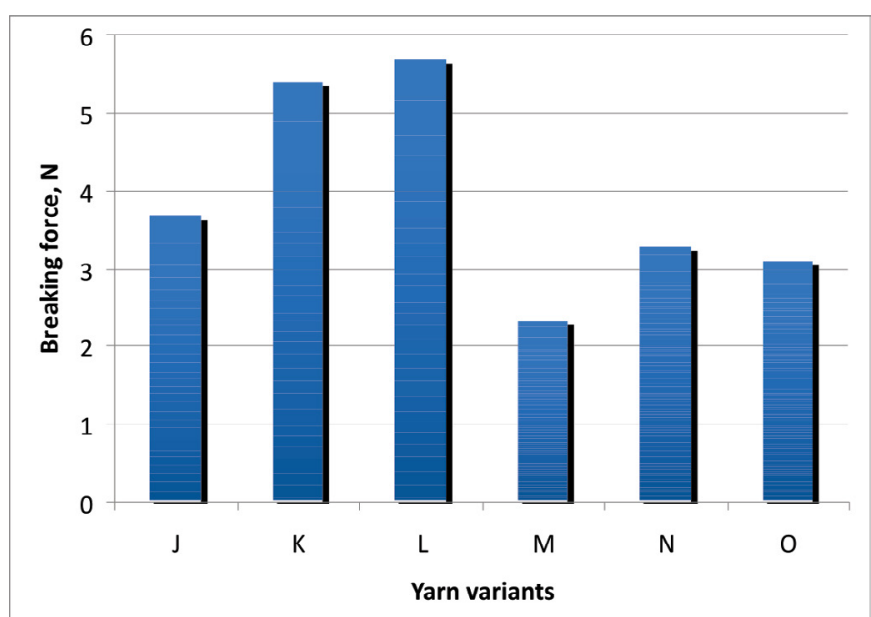

Figure 3. Diagram of yarn breaking force of different raw materials

The column diagram for the yarn breaking force is presented in Figure 3. It can be seen from the diagram that the single yarn $L(100 \%$ flax, dyed in black color) has the highest breaking force $(5.673 \mathrm{~N})$. This result differs only $4.7 \%$ for $100 \%$ flax of natural color $(5.405 \mathrm{~N})$, which is in the second place according to strength. Flax is the strongest natural fiber, so it is natural that the breaking force of yarns $\mathrm{K}$ and $\mathrm{L}$ is the highest. The $\mathrm{J}$ yarn $(100 \%$ bamboo) was in the third place $(3.687 \mathrm{~N})$. Bamboo is a manmade fiber, and the yarn from this fiber has a medium value of breaking force. The breaking force of yarns $\mathrm{N}(70 \%$ flax, $30 \%$ silk $)(3.276 \mathrm{~N})$ and $\mathrm{O}(100 \%$ combed cotton) differs insignificantly (5.4\%). Silk fiber weakens flax/silk yarn in comparison to single flax yarn. Cotton is not such a strong fiber as flax. Plied blended yarn composed of $86 \%$ cotton $/ 14 \%$ polyester has the lowest breaking force $(2.318 \mathrm{~N})$. It can be because of the yarn structure and the quality of the cotton raw material, as well as because the polyester part is very low. Thus, such results can be influenced by the properties of the raw material used in the yarns. As we can see, the main reason for such tendencies is the raw material used in the yarns, because the linear density of all yarns was almost the same. In addition, the $\mathrm{M}$ and $\mathrm{O}$ yarns, which are plied and hence should be stronger, have the lowest breaking force. So, the results are caused by the properties of the raw material. 


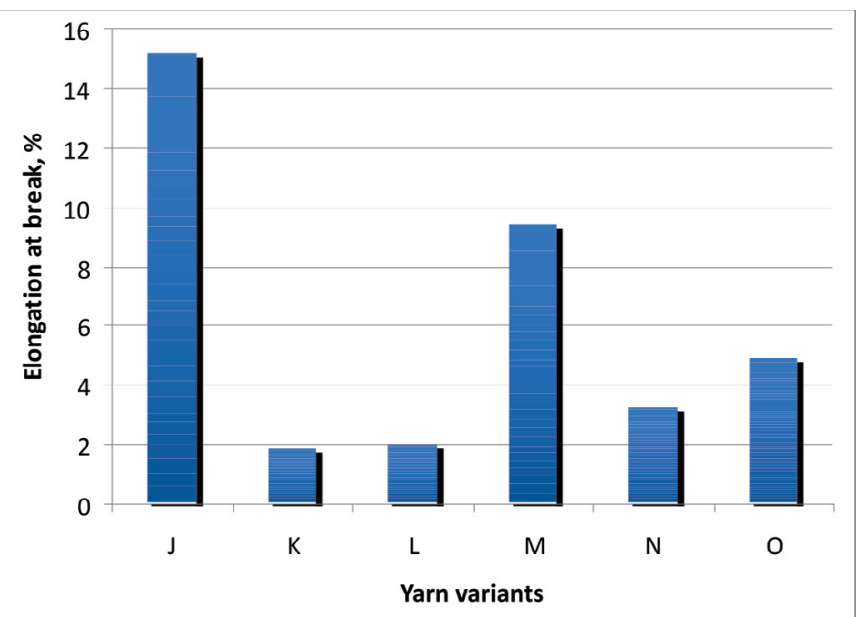

Figure 4. Diagram of yarn elongation at break of different raw materials

Seeking to know if the yarn breaking force depends on the fabric's raw material, the relationships between the yarn breaking force and the raw material density were established. The range of changes in the breaking force varied from $2.3 \mathrm{~N}$ to $5.7 \mathrm{~N}$, but the coefficient of determination was very low $\left(R^{2}=0.2979\right)$. Therefore, it can be said that dependence of the breaking force on the raw material density was not established. These results contradict the statement that a fabric's breaking force depends on the fabric's raw material $[6,7]$, because no correlation between these parameters was established.

Elongation at break is the second important tensile property, which shows a fabric's elasticity. The column diagram of elongation at break for the yarn used for weaving is presented in Figure 4. It can be seen from the diagram, that the single yarn of $\mathrm{J}(100 \%$ bamboo) had the highest elongation at break $(15.19 \%)$. The plied blended yarn $\mathrm{M}$, composed of $86 \%$ cotton $/ 14 \%$ polyester, was in the second place according to elasticity. It can be explained that both these yarns are $(\mathrm{J})$ or have a part (M) of chemical fibers, and chemical fibers have higher elasticity than natural fibers. Yarns N $(70 \%$ flax $/ 30 \%$ silk) and $O(100 \%$ combed cotton) had $3.23 \%$ and $4.92 \%$ elongation at break, respectively. Single yarns of $\mathrm{K}$ and $\mathrm{L}$ (100\% flax) $(1.90 \%$ and $2.03 \%$, respectively) had the lowest elongation at break - elongation at break of dyed $100 \%$ flax yarn was a little higher $(6.4 \%)$ than that of natural-colored yarn. It is understandable, because flax fiber has the lowest elasticity among all natural fibers. The tendencies are caused by the properties of the raw material, because the linear densities of the yarn used were the same. These results confirm the statement in a previous work [5] that the bamboo yarn is the most elastic.

The relationship between elongation at break of the yarn used for weaving and the raw material density was established. Points were distributed randomly, and they did not show any tendencies. They varied over wide ranges (from $1.90 \%$ to $15.19 \%)$. The coefficient of determination was also very low ( $R^{2}=0.10269$ only), and this proved that the dependence of elongation at break on the raw material's density was not established as well. These results also contradict the results in previous publications $[6,7]$.
The tensile characteristics of fabrics woven from the investigated yarns were analyzed further. The coefficient of variation of the breaking force varied from $1.60 \%$ to $12.82 \%$, and the coefficient of variation of the elongation at break varied from $0.32 \%$ to $14.73 \%$. The column diagram of the breaking force of loom state and finished fabrics is presented in Figure 5. It can be seen that the breaking force of loom state woven fabrics of different raw materials was higher than the breaking force of finished fabrics, i.e., fabrics weakened after finishing. It can be because the fabric is affected chemically and mechanically during finishing, and these impacts weakened the fabric. The difference in the breaking force between the loom state and finished fabrics of one part of fabrics $A$ and $D$ was not high (14\% and $13 \%$, respectively). In both of these fabrics, blended yarn was used; thus, the different properties of the different fibers influenced the changes in breaking force after finishing such that they were not significant. However, the differences between the values for other fabrics $(B, C$, $E, F, G$, and $H$ ) were quite high, i.e., they varied from $31 \%$ to $51 \%$. Natural fibers, which have considerable influence on the changes in fabric properties after finishing, were used for all these fabrics. Significant difference $(77 \%)$ between the breaking force of loom state and finished fabrics was obtained for Fabric I, which used $\mathrm{K}$ yarns for the warp and $\mathrm{J}$ yarns for the weft. Bamboo fiber is manmade and very elastic (Fig. 2); so, a considerable change in the breaking force after finishing can be seen in the fabrics made with this raw material. The breaking force of yarns used for weaving was $5.405 \mathrm{~N}$ and $3.687 \mathrm{~N}$, respectively. It can be seen from the diagram in Figure 5 that the finishing of Fabric I reduced the breaking force. Thus, finishing affects the breaking force of a fabric negatively. These results are similar to the results in other papers [1, 2]; the main difference is in the raw material of the fabrics, because in these previous works [1, 2], polyester fabrics were investigated.

It can be seen from Figure 6 that elongation at break of all finished fabrics was higher than that of loom state fabrics. It can be reasoned that yarns in the fabric relaxed and crimped more after finishing and because of that, at first, the yarn extended and then the fabric started to extend as well. Because of this reason, the elasticity of fabrics increases after finishing. The highest difference of elongation at break between loom state and finished fabrics was for Fabric A, for which $\mathrm{N}(70 \%$ flax $/ 30 \%$ silk) yarn was used in the warp and weft directions. Elongation at break of loom state Fabric A was $10.25 \%$ and, after finishing, it increased to $16.76 \%$. Silk gives higher elasticity to blended flax/silk yarn - it is the most elastic natural fiber, and this can be the reason for the significant elasticity changes in the fabric made from these yarns. Moreover, the difference between the elongation at break values of loom state and finished fabrics for fabrics $B$ and $E$ were $34.44 \%$ and $34.55 \%$, respectively. Elongation at break of Fabric I comparing loom state and finished fabrics differs the least - the difference was only $8.4 \%$. Maybe this phenomenon can be influenced by the fact that bamboo fiber is elastic, but the elasticity is expressed more on the loom state fabric than on the fabric after finishing. These results show the same tendencies as reported previously $[3,4]$, in 


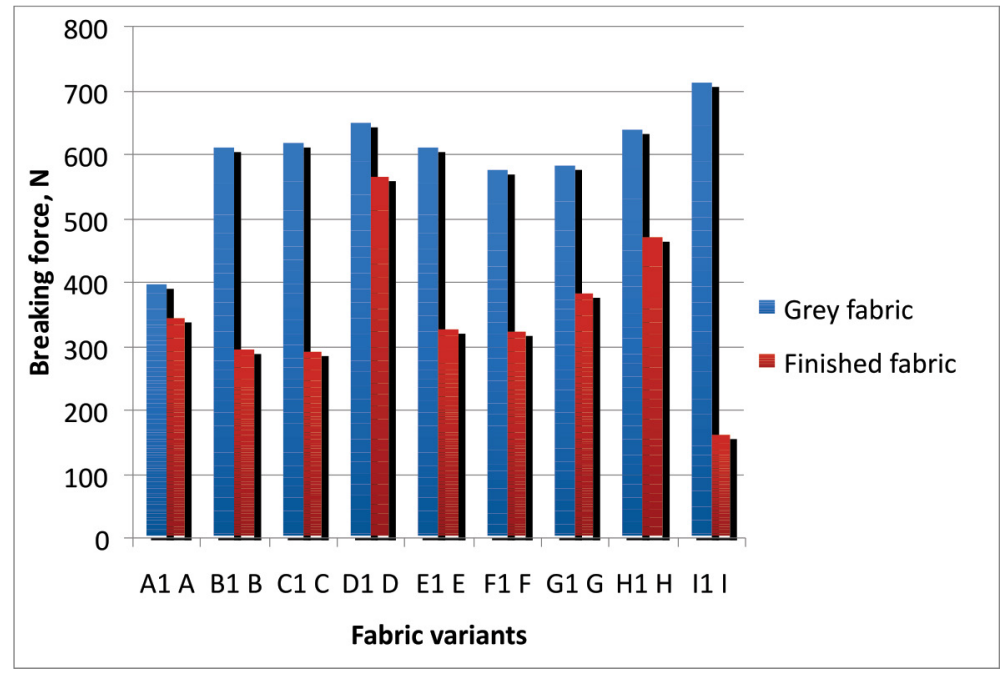

Figure 5. Diagram of breaking forces of fabrics made from different raw materials

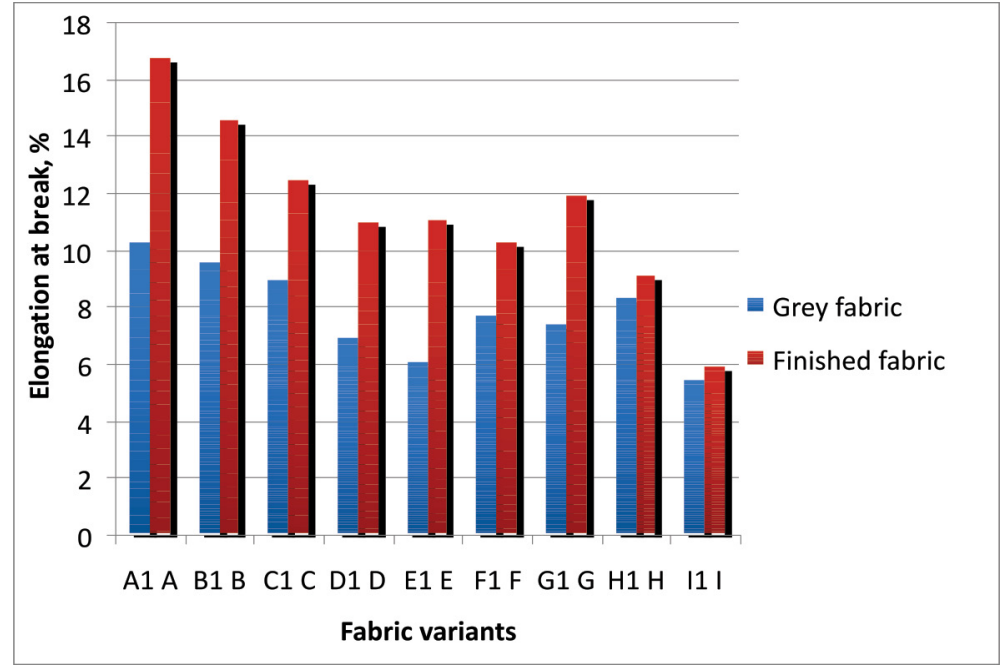

Figure 6. Diagram of elongation at break of fabrics made from different raw materials

which half-wool fabrics were investigated.

Seeking to establish what influence the properties of the yarn used for weaving have on certain fabric properties, the dependencies of the fabric's breaking force on the yarn's breaking force were determined (Figure 7). From the point diagram in Figure 7, it can be seen that points are distributed randomly, and they do not show any tendencies. In addition, the coefficient of determination was very low; thus, it can be said that a correlation between the breaking forces of yarns and fabrics was not established. These results also contradict previous results [6-8], because they show no correlation between the breaking forces of yarns and fabrics. This diagram was built for loom state fabrics, the warp and weft settings of which were the same for all fabrics. We would like to pay attention to the fact that warp and weft settings change only after finishing.

As in the case of the breaking force, a relation between fabrics and yarns' elongation at break was not established, because the coefficient of determination was very low.

In summary, it can be said that a fabric's raw material and the performed finishing influence the fabric's breaking force and elongation at break.

\section{Conclusions}

The breaking force of yarns used for weaving varies from $2.318 \mathrm{~N}$ to $5.673 \mathrm{~N}$. The highest values of breaking force were established for $100 \%$ flax yarn and the lowest values, for $86 \%$ cotton $/ 14 \%$ polyester yarn. This factor is influenced by the properties of the fibers and the yarns made from these fibers.

By analyzing the elongation at break of yarns, it was established that $100 \%$ bamboo and $86 \%$ cotton $/ 14 \%$ polyester yarns are distinguished by extremely high elongation at break. Elongation at break of other yarns was significantly lower. These results can be explained by the fact that part or all yarn has chemical fiber in its composition.

Dependencies of the yarns' breaking forces and elongations at break on the raw material density was not established, because the coefficients of determination were very low $(0.0298$ and 0.1027 , respectively). 


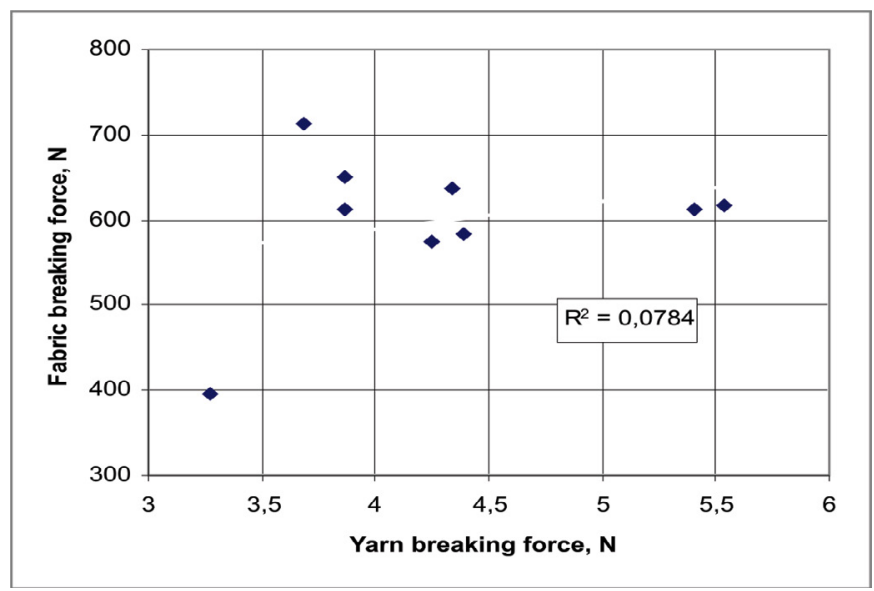

Figure 7. Relation between the breaking forces of yarns and fabrics

The breaking force of fabrics reduced after finishing, because fabrics were affected by different chemical and mechanical impacts during the finishing process.

Elongation at break of fabrics became higher after finishing. At first, the yarns in the fabric were straightened and, subsequently, the structure of the yarns started to change.

Analysis of relationships between the breaking forces of yarns and fabrics and elongations at break showed that there was no correlation between yarns' and fabrics' tensile parameters.

\section{ACKNOWLEDGMENT}

The authors thank the joint-stock company "Klasikinè Tekstile" for help with research materials.

\section{References}

[1] Kumpikaitè, E., Sviderskytè, A. (2006). The influence of woven fabric structure on the woven fabric strength. Materials Science (Medžiagotyra), 12(2), 162-166.

[2] Kumpikaitè, E. (2007a). Analysis of dependencies of woven fabric's breaking force and elongation at break on its structure parameters. Fibres \& Textiles in Eastern Europe, 1(60), 35-38.

[3] Kumpikaité, E. (2007b). The fabric weave's influence on the character of fabric break. Materials Science (Medžiagotyra), 3, 245-248.

[4] Kumpikaitè, E. (2008). Influence of fabric structure on the character of fabric breakage. Fibres \& Textiles in Eastern Europe, 3(68), 44-46.

[5] Rathod, A., Kolhatkar, A. (2014). Analysis of physical characteristics of bamboo fabrics. International Journal of Research in Engineering and Technology, 8, 21-25.
[6] Elnashar, A. E., Dubrovski, P. D. (2008). The influence of the weave and the method of stitching on selected mechanical properties of woven double fabrics. AUTEX Research Journal, 2, 41-43.

[7] Abromavičius, R., Laureckienè, G., Milašius, R. (2011). Influence of yarn texturing technological parameters and fabric structure on tensile properties of the polypropylene fabric. Materials Science (Medžiagotyra), 2, 174-179.

[8] Gabrijelčič, H., Černoša, E., Dimitrovski, K. (2008). Influence of weave and weft characteristics on tensile properties of fabrics. Fibres \& Textiles in Eastern Europe, 2(67), 45-51.

[9] Gunaydin, G. K., Soydan, A. S., Palamutcu, S. (2018). Evaluation of cotton fibre properties in compact yarn spinning processes and investigation of fibre and yarn properties. Fibres \& Textiles in Eastern Europe, 3(129), 23-34.

[10] Azeem, M., Ahmad, Z., Wiener, J., Fraz, A., Siddique, H. F., et al. (2018). Influence of weave design and yarn types on mechanical and surface properties of woven fabric. Fibres \& Textiles in Eastern Europe, 1(127), 42-45.

[11] Zajączkowski, J. (2017). Mathematical modelling of mechanical properties of textiles subjected to tension. Fibres \& Textiles in Eastern Europe, 5(125), 104-106.

[12] Zubair, M., Neckar, B., Malik, Z. A. (2017). Prediction specific stress of cotton staple ring spun yarns: experimental and theoretical results. Fibres \& Textiles in Eastern Europe, 2(122), 43-47.

[13] Matusiak, M., Wilk, E. (2018). Investigation of mechanical and utility properties of two-layer cotton woven fabrics. AUTEX Research Journal, 2, 192-202.

[14] Maqsood, M., Nawab, Y., Shaker, K., Umair, M., Ashraf, M., et al. (2016). Modelling the effect of weave structure and fabric thread density on mechanical and comfort properties of woven fabrics. AUTEX Research Journal, 3, 160-164.

[15] Penava, Ž., Šimic Penava, D., Tkalec, M. (2016). Experimental analysis of the tensile properties of painting canvas. AUTEX Research Journal, 4, 182-195.

[16] Matusiak, M., Frącczak, L. (2016). Influence of kind of weft yarn on properties of the Seersucker woven fabrics. AUTEX Research Journal, 4, 214-221.

[17] International standard LST EN ISO 139: 2005/A1: 2011. Textiles - Standard atmospheres for conditioning and testing.

[18] International standard LST EN ISO 2062. Textiles - Yarns from packages - Determination of single-end breaking force and elongation at break using constant rate of extension (CRE) tester.

[19] International standard ISO 13934-1:1999 Textiles - Tensile properties of fabrics - Part 1: determination of maximum force and elongation at maximum force using the strip method. 